\title{
Unusual complication of coumadin toxicity mimicking Crohn's disease
}

\author{
Suat Keskin, İbrahim Erdem Gökmen, Osman Koç, Orhan Özbek
}

Department of Radiology, Necmettin Erbakan University, Meram School of Medicine, Konya, Turkey

\section{Correspondence to} Dr Suat Keskin drsuatkeskin@yahoo.com

Accepted 7 June 2014

\section{DESCRIPTION}

Spontaneous small bowel haematoma and haemoperitoneum are uncommon complications of coumadin toxicity. We present two cases of spontaneous small bowel haematoma related to coumadin toxicity. The clinical and imaging findings of this entity are discussed.

Case 1: A 51-year-old woman presented to the emergency department with the symptoms of abdominal pain and nausea. The patient showed the following vital signs: blood pressure 145/ $95 \mathrm{~mm} \mathrm{Hg}$, pulse rate $100 \mathrm{bpm}$, temperature $37.5^{\circ}$ $\mathrm{C}$ and $100 \%$ oxygen saturation. She had hypertension and was on coumadin due to atrial fibrillation. She had undergone mitral and aortic valve replacement previously. The patient had no other symptoms such as melena or haematochezia. Laboratory studies showed an elevated leucocytosis. Her haemoglobin level was $11.5 \mathrm{~g} / \mathrm{dL}$. Coagulation tests were abnormal with an International Normalised Ratio (INR) of 3.14 IU (1-1.5), a prolonged activated partial thromboplastin time of $>110(26-35.5)$ s and a prothrombin time of $30.6(11-15)$ s. Abdominal CT was performed because of ongoing abdominal pain and sensitivity to palpation. CT scan demonstrated diffuse, symmetrical and oedematous thickening of the wall of the terminal ileum, reaching $9 \mathrm{~mm}$. Fluid collections were found adjacent to the serosa compatible with intestinal bleeding (figure 1A). Laparoscopic intervention later showed discolouration of the intestinal wall and blood was leaking through the bowel wall into the peritoneal cavity. Warfarin was withdrawn immediately and decompression applied with a nasogastric catheter. The patient was treated with fresh-frozen plasma and intravenous fluids. She recovered completely within 8-9 days. Follow-up CT scan after a month showed complete regression of bowel wall thickening and ascites.
Case 2: A 60-year-old man presented with a deteriorating general condition. The patient was receiving coumadin for the treatment of deep vein thrombosis. There were no gastrointestinal symptoms such as melena or haematochezia. Owing to the decrease in haemoglobin levels from 14 to $11 \mathrm{~g} / \mathrm{dL}$, a CT scan was performed. Laboratory studies also showed remarkable leucocytosis. The INR and prothrombin time on admission were 3.49 IU (1-1.5) and 20.1 (11-15) s, respectively. As in the aforementioned case, CT images demonstrated oedematous thickening of the wall of distal ileum along with haemoperitoneum (figure 1B). Decompression was applied with a nasogastric catheter. The patient was successfully cared for with medical treatment (intravenous fluids, vitamin $\mathrm{K}$, packed red blood cell transfusion and frozen fresh plasma). Oral nutrition was initiated 3 days later. The patient was discharged within 4-5 days.

Coumadin toxicity may cause serious and lifethreatening complications. The most common complications are gastrointestinal such as haematemesis and melena. Upper gastrointestinal tract (\%52), lower gastrointestinal tract $(\% 18)$, soft tissues $(\%$ $<7)$ rectus abdominis muscle $(\%<4)$, retroperitoneum $(\%<4)$, haemoperitoneum $(\%<4)$, intestinal wall $(\%<2)$ and solid organs $(\%<2)$ are identified as the sources of bleeding. ${ }^{1}$

Incidence of spontaneous small bowel haematoma related to coumadin toxicity is reported to be $1: 2500$. The jejunum is often affected whereas the duodenum and ileum are rarely affected. ${ }^{2}$

Samie and Theilmann ${ }^{2}$ reported that haemorrhage originates in the submucosa. Haematoma leads to expansion in the intestinal wall and changes in the osmotic gradient. Dibbad et $a l^{3}$ have mentioned that haemorrhage originates in the submucosal or subserosal small vessels. Leakage of the blood into the peritoneal cavity leads to haemoperitoneum and peritoneal irritation.
To cite: Keskin $S$, Gökmen IE, Koç O, et al. BMJ Case Rep Published online: [please include Day Month Year] doi:10.1136/ bcr-2013-202755

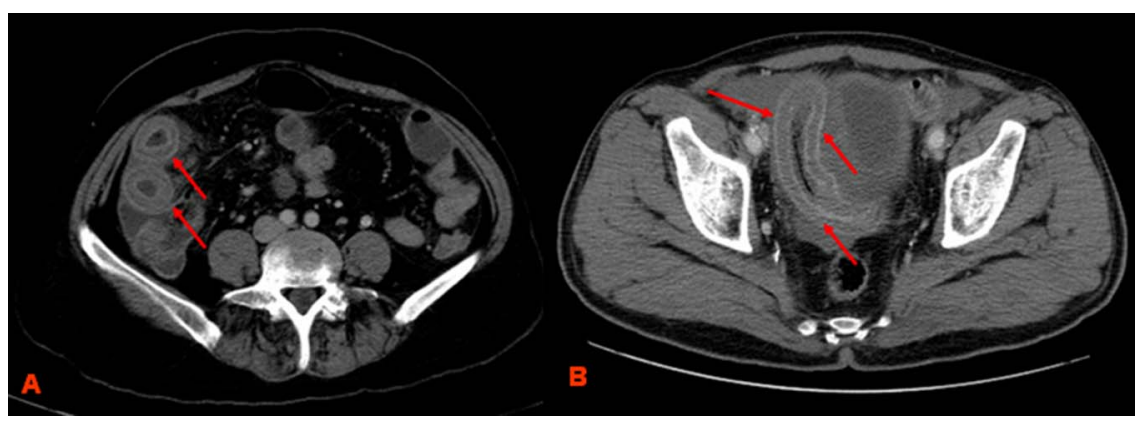

Figure 1 Transverse CT images at level of terminal ileum show bowel wall thickening and haemoperitoneum adjacent bowel loops in (A) a 51-year-old woman with a history of aortic-mitral valve replacement. (B) and in a 60 -year-old man using coumadin. 
CT is the key for the diagnosis of coumadin toxicity with findings including intramural hyperdensity, luminal narrowing and circumferential wall thickening. Hyperdense wall thickening is pathognomonic for intestinal haematoma. But with lyses of the clot attenuation decreases, as in our cases, and it may not be distinguishable from other causes of distal ileal disease such as Crohn's disease. When a thickened intestinal wall with low attenuation is detected on CT, Crohn's disease and coumadin toxicity-related intestinal haematoma should be kept in the differential diagnosis. Where CT is unavailable ultrasound may be used to diagnose intestinal haematoma. Sonography may show circumferential wall thickening of the bowel wall. Anechoic or

\section{Learning points}

- Coumadin toxicity may cause blood leakage through small vessels of intestinal serosa into the peritoneum.

- lleum is rarely affected in patients with intestinal bleeding secondary to coumadin toxicity.

- Coumadin toxicity leading to the involvement of the terminal ileum should be considered in the differential diagnosis of Crohn's disease. hypoechoic halo signs may be seen depending on the age of haemorrhage. ${ }^{3}$

Early diagnosis is necessary because most patients can be treated without surgery. During treatment, anticoagulant drugs are discontinued first, oral intake is stopped and nasogastric decompression is applied. Symptoms usually regress within 2-3 days after medical treatment (vitamin $\mathrm{K}$, frozen fresh plasma, packed red blood cell transfusion). A conservative approach is suggested treatment if all other associated complications have been excluded. Complications that require surgery are haemoperitoneum, ischaemia, perforation, peritonitis and intestinal obstruction.

Contributors IEG and OÖ diagnosed the patients and prepared the article. SK and OK helped to prepare the article.

Competing interests None.

Patient consent Obtained.

Provenance and peer review Not commissioned; externally peer reviewed.

\section{REFERENCES}

1 Kostka R, Havluj L, Jirava D, et al. Hemorrhagic complications of warfarin therapy. Rozhl Chir 2010:89:124-9.

2 Abdel Samie A, Theilmann L. Detection and management of spontaneous intramural small bowel hematoma secondary to anticoagulant therapy. Expert Rev Gastroenterol Hepatol 2012;6:553-8.

3 Dibbad R, Deshmukh M, Merchant $\mathrm{H}$, et al. Spontaneous intramural hematoma of the small bowel-a complication of anticoagulant therapy. Internet J Radiol 2010;12:1.

Copyright 2014 BMJ Publishing Group. All rights reserved. For permission to reuse any of this content visit

http://group.bmj.com/group/rights-licensing/permissions.

BMJ Case Report Fellows may re-use this article for personal use and teaching without any further permission.

Become a Fellow of BMJ Case Reports today and you can:

- Submit as many cases as you like

- Enjoy fast sympathetic peer review and rapid publication of accepted articles

- Access all the published articles

- Re-use any of the published material for personal use and teaching without further permission

For information on Institutional Fellowships contact consortiasales@bmjgroup.com

Visit casereports.bmj.com for more articles like this and to become a Fellow 